\title{
A Case Report of a Metastatic Primary Gastric Lymphoma; Diffuse Large B-Cell or Burkitt Lymphoma?
}

\author{
Hasan Jalaeikhoo ${ }^{1}$, Mohsen Rajaeinejad ${ }^{1}$, Manoucher Keyhani ${ }^{2}$, Mahsa \\ Keshavarz-Fathi ${ }^{3,4,{ }^{*}}$
}

${ }^{1}$ AJA Cancer Research Center, AJA University of Medical Sciences, Tehran, Iran

${ }^{2}$ Hematology and Oncology Research Center Vali-Asr Hospital, Tehran University of Medical Sciences, Tehran, Iran

${ }^{3}$ School of Medicine, Tehran University of Medical Sciences, Tehran, Iran

${ }^{4}$ Cancer Immunology Project, Universal Scientific Education and Research Network, Tehran, Iran

* Corresponding author: Mahsa Keshavarz-Fathi, School of Medicine, Tehran Universi-

DOI: $10.21859 / \mathrm{mci}-01022$ ty of Medical Sciences, Tehran, Iran.E-mail: mahsa.keshavarz20@gmail.com

Submitted: 4 December 2016

Revised: 15 January 2017

Accepted: 3 February 2017

ePublished: 11 March 2017

Keywords:

MYC

Burkitt Lymphoma

Tumor Lysis Syndrome

Diffuse Large B-cell Lymphoma

\begin{abstract}
Introduction: Primary gastric lymphoma (PGL) is a rare tumor, whose differential diagnosis may become complicated without precise immunohistochemistry (IHC) and genetic analysis.

Case Presentation: A 33-year-old woman presented with gastric cancer and had undergone gastrectomy without precise IHC and staging in another center. Inappropriate IHC after surgery showed diffuse large B-cell lymphoma. After her admission to our center, due to gastrointestinal (GI) symptoms further evaluations were performed, leading to application of chemotherapy and radiotherapy regimens. In the next admissions, involvement of tibia, jaw, and gingiva took place and Burkitt lymphoma was diagnosed with precise IHC panel, which made alteration in the treatment. In the last admission, she expired due to renal failure and tumor lysis syndrome.

Conclusions: There was some mismanagement in this case, especially incomplete and inappropriate IHC panel, which led to wrong diagnosis.
\end{abstract}

(C) 2017. Multidisciplinary Cancer Investigation

\section{INTRODUCTION}

Gastrointestinal (GI) tract is one of the most common sites of extranodal non-Hodgkin lymphoma (NHL). Stomach is the most frequent site for gastric lymphoma (40\%). However, primary gastric lymphoma is a rare tumor in the digestive tract, which accounts for less than $5 \%$ of all primary malignancies of the stomach $[1,2]$.

\section{CASE PRESENTATION}

A 33-year-old woman presented with epigastric pain, nausea, few episodes of vomiting, questionable history of melena, anorexia, and $5 \mathrm{~kg}$ (10 lb) weight loss in the preceding two months. Past medical and family history were negative. Upper GI endoscopy showed a large mass in the antrum of the stomach. Pathological analysis of the specimen was suggestive of poorly differentiated carcinoma. The patient was referred to the surgery ward for resection after one month. Laboratory data was as follows: white blood cell (WBC) count 8000/ $\mu \mathrm{L}$ (normal range: 4000$10000 / \mu \mathrm{L})$, hemoglobin $(\mathrm{Hb})$ concentration $11.8 \mathrm{~g} / \mathrm{dL}$ (normal range: $12-15 \mathrm{~g} / \mathrm{dL}$ ), mean corpuscular volume (MCV) 81.6 FL (normal range: $80-100 \mathrm{FL}$ ), platelet (Plt) count 341000/ $\mu \mathrm{L}$ (normal range: 150000-450000/ $\mu \mathrm{L}$ ), partial thromboplastin time (PTT) 26 seconds (normal range: $25-35$ seconds), international normalized ratio (INR) $1 \mathrm{~nL}$ (normal range: $0.8-1.2 \mathrm{~nL}$ ), hepatitis $B$ surface antigen (HBs-Ag) negative, hepatitis $\mathrm{C}$ virus antibody (HCV-Ab) negative, liver function test as well as renal function tests were normal. She underwent near total gastrectomy. The patient was well in the hospital course except for developing melena, for which two units of packed cell were transfused. She was discharged with pantoprazole, metronidazole, and cefazolin. Pathology of the removed tissue demonstrated a $10 \times 6 \times 4 \mathrm{~cm}$ ulcerated tumor in the greater curvature, continued to the lesser curvature. The mass was extended along the full thickness of the gastric wall. There were also 10 perigastric lymph nodes diametered $\leq 1.5 \mathrm{~cm}$. The omentum and lymph nodes were invaded by the tumoral tissue. The proximal and distal surgical margins were tumor free. Pathology revealed malignant round cell tumor, most probably lym- 
phoma. The result of immunohistochemistry (IHC) was reactive for LCA, CD20 and 80\% positive for Ki67 and negative for $\mathrm{CD} 3, \mathrm{CK}$, and EMA markers. The diagnosis of diffuse large B-cell lymphoma was established. Seventeen days after the surgery, the patient was admitted to our hospital for the first time with some complaints including severe abdominal pain, nausea, vomiting, and diarrhea. Positive finding in physical examination revealed dehydration, abdominal distention, positive shifting dullness, and oral temperature of $38^{\circ} \mathrm{C}$. Abdominal sonography showed moderate ascites. The abnormal laboratory data were reported as follows: WBC $11100 / \mu \mathrm{L}, \mathrm{Hb} 11.8$ $\mathrm{g} / \mathrm{dL}$, erythrocyte sedimentation rate (ESR) $38 \mathrm{~mm} /$ hour (normal range: $1-20 \mathrm{~mm} /$ hour), uric acid $14 \mathrm{mg}$ / $\mathrm{dL}$, then increased to $16 \mathrm{mg} / \mathrm{dL}$ (normal range: 2.3-6.1 $\mathrm{mg} / \mathrm{dL}$ ), blood urea nitrogen (BUN) $21 \mathrm{mg} / \mathrm{dL}$, then increased to $127 \mathrm{mg} / \mathrm{dL}$ (normal range: $7-20 \mathrm{mg} / \mathrm{dL}$ ), creatinine $(\mathrm{Cr}) 1 \mathrm{mg} / \mathrm{dL}$, then increased to $3 \mathrm{mg} / \mathrm{dL}$. With regards to the mentioned lab data, medical oncology, GI and nephrology consultations were requested. This was the first time we visited the patient. Prognostic tests were requested: lactic acid dehydrogenase (LDH) $1393 \mathrm{U} / \mathrm{L}$ (140-280 U/L) and beta 2 microglobulin $3.8 \mathrm{mg} / \mathrm{L} \mathrm{(<}$ $2 \mathrm{mg} / \mathrm{L}$ ). The endoscopy result was normal. However, paracentesis of $2500 \mathrm{~mL}$ abdominal fluid was performed and cytologic assessment was positive for lymphomatous involvement. However, bone marrow aspiration (BMA) and bone marrow biopsy (BMB) were normal. R-CHOP regimen (rituximab, cyclophosphamide, hydroxydaunorubicin, oncovin (vincristine), and prednisone) was started for the patient. She received R-CHOP every three weeks on an outpatient basis. After four cycles, she was evaluated and reported with normal computed tomography (CT) scan of the neck, chest, abdomen, and pelvis. BMA, BMB, liver function tests (LFT) and renal function tests (RFT) were normal as well. Nevertheless, PETCT was not available. The regimen proceeded for two more cycles.

Three months later, she presented with progressive and severe bone pain in the right tibia, disabling her from walking. Tenderness and hotness were obvious in the right lower extremity. The whole body bone scan was performed and metabolic active lesions in the right tibia and the left ninth rib were detected. Bone marrow biopsy of the right tibia confirmed malignant involvement of its mid-shaft and made her get radiation therapy regimen, $4500 \mathrm{Rad}$ in 10 successive sessions, and two R-ICE (rituximab, ifosfamide + mesna, carboplatin, etoposide) regimen cycles. Two months later she developed severe pain in the right jaw. Biopsy of the right gingiva and jaw in another medical center also showed diffuse large B-cell lymphoma (DLBCL). She was admitted to the hospital and received a new chemotherapy regimen. E-SHAP which includes etoposide, solumedrol (methyl prednisolone), high-dose ARA-C and platinum (cisplatin) was prescribed for three cycles. Pathological reviews of the jaw and right gingiva specimens were conducted in another hospital and the result was compatible with Burkitt lymphoma (BL).

Immunohistochemical studies had the following results: positive for CD20 and CD10, negative for CD3, BCL2, CD34, and TdT, while Ki67 showed proliferative activity in $100 \%$ of the tumor nuclei (Figure 1).

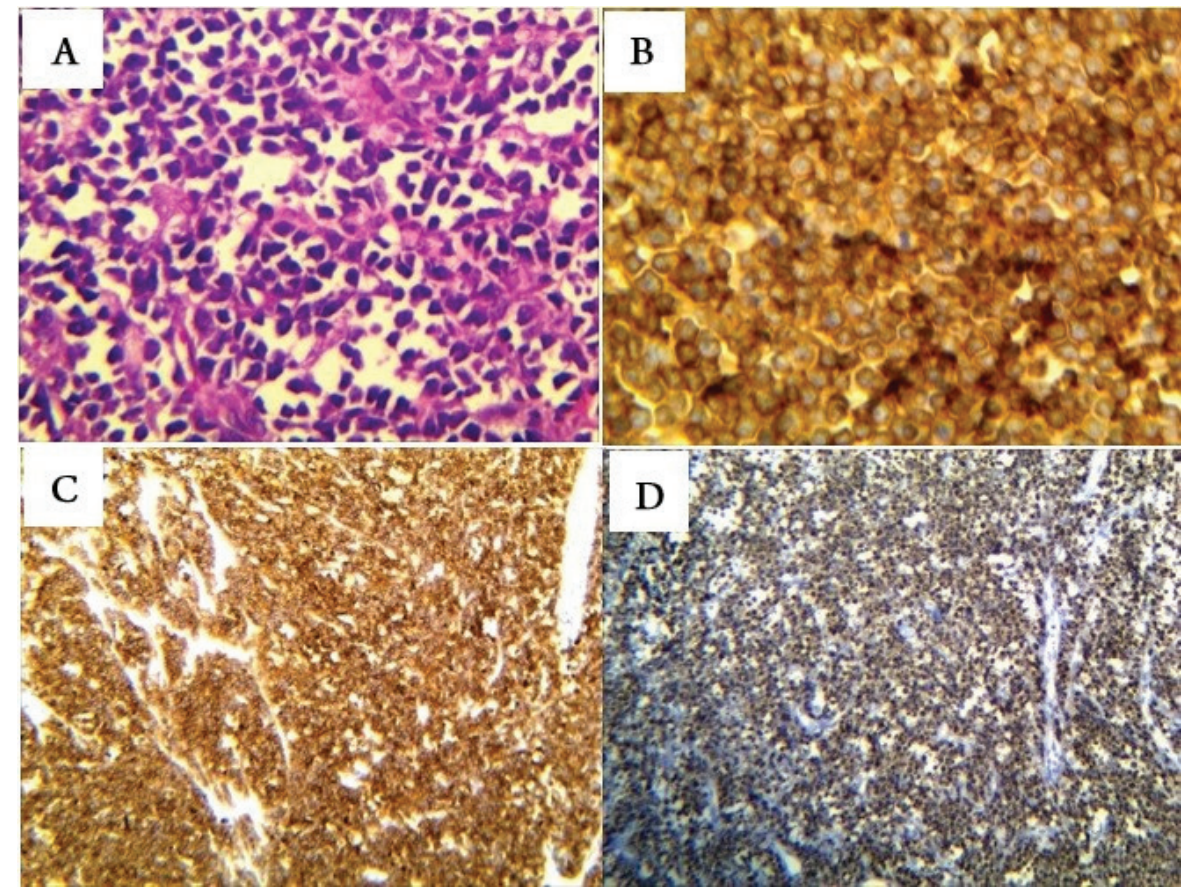

Figure 1: Pathological and Immunohistochemical Assessments of the Specimen Illustrated Burkitt Lymphoma

(A) Hematoxylin \& Eosin staining of the specimen shows round cell tumor; (B) reactivity to CD20; (C) reactivity to CD 10; (D) reactivity to Ki67 
For the fourth time, the patient was admitted to the hospital with intense abdominal pain, nausea, and vomiting. She had normal LFT, RFT, serum amylase level, and complete blood count (CBC) except for $\mathrm{Hg}$ which was 9. CT of the abdomen and pelvis showed a lobulated hypo-dense enhancing mass pushing gallbladder, normal pelvic organs and no ascites. Lumbar puncture (LP) was normal. High-dose MTX, high-dose ARA-C and intrathecal chemotherapy were initiated for the patient.

Two months later, she was admitted to the hospital for the fifth time, due to severe abdominal pain and distention, vomiting, and decreased urine output. Blood pressure was $80 / 50$ and pulse rate was 120 . She gradually developed confusion and coma. Abdominal sonography showed multiple space occupying lesions (SOL) of the liver and ascites. Laboratory findings represented tumor lysis syndrome: $\mathrm{WBC}=4600 / \mu \mathrm{L}, \mathrm{Hb}=10.9$ $\mathrm{g} / \mathrm{dL}, \mathrm{PLT}=102000 / \pi \mathrm{L}, \mathrm{ESR}=79 \mathrm{~mm} /$ hour, $\mathrm{K}^{+}=6$ meq $/ \mathrm{L}, \mathrm{Na}^{+}=135 \mathrm{meq} / \mathrm{L}, \mathrm{Ca}^{2+}=6 \mathrm{mg} / \mathrm{dL} \mathrm{Po}_{4}{ }^{3-}=7$ $\mathrm{mg} / \mathrm{dL}$, uric acid $=16.5 \mathrm{mg} / \mathrm{dL}, \mathrm{BUN}=251 \mathrm{mg} / \mathrm{dL}$, $\mathrm{Cr}=4.7 \mathrm{mg} / \mathrm{dL}$. Ascetic fluid examination was cloudy, $\mathrm{WBC}=27500 / \mu \mathrm{L}$ with $96 \%$ lymphocyte, Glucose $=25 \mathrm{mg} / \mathrm{dL}$, protein $=4.7 \mathrm{~g} / \mathrm{dL}$. Due to renal failure and possible tumor lysis syndrome, hemodialysis was performed as a chosen treatment. However, she died in deep coma 10 days after admission.

\section{DISCUSSION}

Primary gastric lymphoma (PGL) can be manifested like other benign or malignant disorders in the GI. Epigastric pain, anorexia, weight loss, GI bleeding, nausea, and vomiting are the common symptoms $[3,4]$. Histopathological assessment makes the impression of the PGL. However, confirmation of PG-DLBCL is made based on IHC or MYC rearrangement evaluation. IHC may show another diagnosis for pathologically diagnosed poorly differentiated carcinomas, as it was reported for $18 \%$ of cases in a study [5]. Positive CD20 or pan B-cell markers, CD19, CD20, CD22, as well as positive $\mathrm{BCl}-6$ are commonly reported in $\mathrm{IHC}$ of both $\mathrm{BL}$ and DLBCL. In order to distinguish these two types of lymphoma by IHC, the panel must include CD10, BCL-2 and Ki67, given that most of BL cases show high reactivity for CD10 and Ki67, whereas only a few BL cases are reactive for BCL2. In contrast, DLBCL shows opposite results for these markers [6].

Staging of the PG-DLBCL is performed by consideration of the imaging studies, as well as bone marrow aspiration and biopsy. According to the Lugano staging, DLBCL stage I is limited to the GI tract, stage II is extended to the abdomen, stage IIE is defined as adjacent tissue involvement by serosa penetration, and stage IV disseminates to extra-nodal regions or is concomitant supra-diaphragmatic nodal involvement $[7,8]$.

The international prognostic index (IPI) in case of PGL is calculated considering the following factors: age $>60$ years, increased serum LDH, performance status $\geq 2$, more than one extra-nodal involvement excluding the stomach, and stage III-IV of the disease [9]. Moreover, $\beta-2$ microglobulin, albumin and hemoglobin levels are correlated with longer overall survival and event-free survival [9-11]. Risk of CNS involvement in two years was $10.2 \%$ in this patient.

The first choice of treatment for PG-DLBCL is chemotherapy based on age, IPI, and dose adjustment. The CHOP chemotherapy regimen is typically administrated for NHLs. Rituximab as a monoclonal antibody against the CD20 molecule on the B-cell surface can be added to this regimen. For relapsed or refractory lymphomas, ICE chemotherapy regimen in combination with or without rituximab and ESHAP regimen are applied $[12,13]$.

Similarly, treatment for BL is chemotherapy and in some conditions combination of chemotherapy and radiotherapy. Tumor lysis syndrome (TLS) may happen in the patients with hematological cancers, especially in tumors with high proliferation rates like BL, spontaneously or while receiving chemotherapy agents. Therefore, one of the first steps in management of $\mathrm{BL}$ is prevention of TLS by administration of medications such as allopurinol or rasburicase [14].

For prevention of wrong diagnosis, we have to consider the most appropriate approach. In the case described above, the most important pitfall was incomplete and inappropriate usage of IHC panel.

\section{ACKNOWLEDGMENTS}

Not Applicable.

\section{CONFLICTS OF INTEREST}

The authors declared that there was no conflict of interests.

\section{ETHICS APPROVAL}

Not applicable.

\section{REFERENCES}

1. Chihara D, Oki Y, Ine S, Kato H, Onoda $\mathrm{H}$, Taji $\mathrm{H}$, et al. Primary gastric diffuse large B-cell Lymphoma (DLBCL): analyses of prognostic factors and value of pretreatment FDG-PET scan. Eur J Haematol. 2010;84(6):493-8. DOI: 10.1111/j.1600-0609.2010.01426.x PMID: 20148943

2. Al-Akwaa AM, Siddiqui N, Al-Mofleh IA. Primary gastric lymphoma. World J Gastroenterol. 2004;10(1):5-11. PMID: 14695759

3. Bismar MM, Alasadi M, Hendawy BS, Waness A. A case of successful remission of extensive primary gastric diffuse large B cell lymphoma: radiologic, endoscopic and pathologic evidence. Case Rep Gastroenterol. 2014;8(1):134-40. DOI: 10.1159/000362537 PMID: 24847196

4. Boot H, de Jong D. Diagnosis, treatment decisions, and follow up in primary gastric lymphoma. Gut. 2002;51(5):621-2. PMID: 12377794

5. Hainsworth JD, Wright EP, Johnson DH, Davis BW, Greco 
FA. Poorly differentiated carcinoma of unknown primary site: clinical usefulness of immunoperoxidase staining. J Clin Oncol. 1991;9(11):1931-8. DOI: 10.1200/JCO.1991.9.11.1931 PMID: 1941051

6. Nakamura N, Nakamine H, Tamaru J, Nakamura S, Yoshino T, Ohshima K, et al. The distinction between Burkitt lymphoma and diffuse large B-Cell lymphoma with c-myc rearrangement. Mod Pathol. 2002;15(7):771-6. DOI: 10.1097/01. MP.0000019577.73786.64 PMID: 12118116

7. Selcukbiricik F, Tural D, Elicin O, Berk S, Ozguroglu M, Bese $\mathrm{N}$, et al. Primary gastric lymphoma: conservative treatment modality is not inferior to surgery for early-stage disease. ISRN Oncol. 2012;2012:951816. DOI: 10.5402/2012/951816 PMID: 22988526

8. Hung YS, Lin TL, Kuo MC, Tang TC, Dunn P, Wang PN, et al. Primary gastric diffuse large B-cell lymphoma. Chang Gung Med J. 2008;31(2):159-66. PMID: 18567416

9. Rotaru I, Gaman GD, Stanescu C, Gaman AM. Evaluation of parameters with potential prognosis impact in patients with primary gastric diffuse large B-cell lymphoma (PG-DLBCL). Rom J Morphol Embryol. 2014;55(1):15-21. PMID: 24715160

10. Sohn BS, Kim SM, Yoon DH, Kim S, Lee DH, Kim JH, et al. The comparison between CHOP and R-CHOP in primary gastric diffuse large B cell lymphoma. Ann Hematol. 2012;91(11):1731-9. DOI: $10.1007 / \mathrm{s} 00277-012-1512-4$ PMID: 22752193

11. Mehmet K, Sener C, Uyeturk U, Seker M, Tastekin D, Tonyali $\mathrm{O}$, et al. Treatment modalities in primary gastric lymphoma: the effect of rituximab and surgical treatment. A study by the Anatolian Society of Medical Oncology. Contemp Oncol (Pozn). 2014;18(4):273-8. DOI: 10.5114/wo.2014.40556 PMID: 25258586

12. Sarid N, Joffe E, Gibstein L, Avivi I, Polliack A, Perry C, et al. Reduced-dose ICE chemotherapy +/- rituximab is a safe and effective salvage therapy for fit elderly patients with diffuse large B-cell lymphoma. Leuk Lymphoma. 2016;57(7):16339. DOI: 10.3109/10428194.2015.1106532 PMID: 26643787

13. Choi CW, Paek CW, Seo JH, Kim BS, Shin SW, Kim YH, et al. ESHAP salvage therapy for relapsed or refractory non-Hodgkin's lymphoma. J Korean Med Sci. 2002;17(5):621-4. DOI: 10.3346/jkms.2002.17.5.621 PMID: 12378012

14. Miles RR, Arnold S, Cairo MS. Risk factors and treatment of childhood and adolescent Burkitt lymphoma/leukaemia. Br J Haematol. 2012;156(6):730-43. DOI: 10.1111/j.13652141.2011.09024.x PMID: 22260323 